Canadian Journal of Family and Youth, 13(3), 2021, pp. 22-31

ISSN 1718-9748C University of Alberta

http://ejournals,library,ualberta.ca/index/php/cjfy

\title{
Women in Love: Why Women are Expected to Love First and the Exploration of Changing Gender Roles in Heterosexual Romantic Relationships
}

\author{
Isabelle Kuzio $^{1}$
}

\begin{abstract}
This paper explores the misconception that women, being perceived in western society as the most emotional gender, is the first to feel love and to say the words "I love you" in a romantic heterosexual relationship. Research has determined that women are expected to say and feel love in a relationship before men, when in reality the opposite is true. I will discuss social expectations of gender norms in heterosexual relationships and the ways in which relationship norms are currently being challenged. I suggest that changes in courtship norms and media influences on youth create inaccurate gender expectations around love and that new technological advances and decrease in the effectiveness of monogamous heterosexual relationships are challenging these gender expectations, therefore the relationship model and the gendered expectations within these relationships, as known by western society, may be obsolete.
\end{abstract}

\footnotetext{
${ }^{1}$ MacEwan University
} 


\section{Introduction}

The concept of love is one that is difficult to define in just one way as it contains multiple meanings. The term "love" can apply to the care of a friend or a pet, the affection toward family members, sexual attraction, falling in love and the intense feelings of affection for another person that may be fleeting or last forever. Regardless of the meaning, most people have experienced some form of love in their lifetime and often more than once. It can be agreed that love is one the most important emotions for humans particularly in intimate relationships as it can cause the attraction to another person, leading to flirtation, dating and sometimes marriage (Schmitt et al., 2009). The three words often found to be most important in progressing a romantic relationship are "I love you", which researchers have found to differ in use and frequency between males and females in heterosexual relationships (Harrison \& Shortall, 2011).

There is a gendered difference between males and females in the use of the word "love" as found by researchers Tucker and Yuhas-Byers who asked women and men to list acts of romance in a relationship (Tucker, Marvin \& Vivian, 1991). As a result, saying "I love you" was in the top 10 romantic acts as chosen by women, but did not make the top 10 on the list for men, suggesting that there is an emotional difference between men and women in heterosexual romantic relationships with regards to the use of the phrase "I love you" (Tucker et al., 1991). However, in research conducted by Harrison and Shortall, they found that although it is expected that women feel and say "I love you" first in a romantic relationship, men reported feeling love sooner than women did, and $64 \%$ of men in the sample reported saying "I love you" before their female partner in their most recent relationship (2011).

In this paper, I will suggest reasons as to why there is a disparity between the gendered expectations of saying and feeling love first. Love is one of the most crucial progressions of a romantic relationship, and thus the gendered expectations in said relationship can prove to be just as significant. Therefore, I propose that the expectation that women say and feel love before men in a heterosexual relationship in western society is upheld by, but is not limited to, courtship norms and the early introduction of visual media to the current demographics that engage in heteronormative dating. Furthermore, I believe it is necessary to examine how the advancement of technology and beliefs in monogamy are challenging the gendered expectations of love.

\section{Literature Review}

Saying "I love you" is one of the most important steps of progression in a dating relationship, and who says it first can be important. Expressing or feeling love in a relationship before the other person is ready is often crucial to the solidity of a relationship. There is a common misconception that women are more eager and more likely to feel love and say those three important words first; however, research done by Harrison and Shortall discovered that of 172 college students, men reported falling in love more quickly than women and more men reported saying "I love you" first in the relationship than females (2011). A study conducted by Tucker, Marvin and Vivian studied what constitutes an act of love, finding that women believe saying "I love you" is 
more important than men do (1991). This may be due to the fact that it is expected for women to say "I love you" first, and therefore it is seen as less special of an act, although this is speculation and the real reason requires more research. Researchers have left the question as to why there is a disparity between who realistically says and feels love first and who is expected to say and feel love first in a relationship. This is the question I am intrigued to answer.

Interestingly, more research has been and continues to be done on the effects of media on children's beliefs and understandings around emotion and masculinity and femininity (Yakal1Çamoğlu, 2019). A study concluded that the portrayal of the princess in need of a prince who will surrender to her becomes the ideal of love, whereas the boys dislike the portrayal of the prince and prefer the brave superhero, therefore becoming disappointed with the girls 'ideals of love (Yakal1Çamoğlu, 2019). This research has set out to explain that the difference between boy's and girl's expectations of affection and love, however I believe it is most helpful in describing the early exposure to gender roles within relationships.

Durik, Hyde, Marks, Roy, Anaya and Schultz found that in a variety of cultures, emotions expected to be expressed by men and by women differed somewhat (2006). The expectation for women to show the emotion of love, rather than men, was consistent between all cultural groups examined (Durik et al., 2006). Though in the 21st century it is expected that women show and feel love first in most cultures, this was not always the case. In mid-twentieth century England, courting a woman was a way of changing (often for the better) one's status and identity (Langhamer, 2007). Much research has been done on the historic rules and rituals of dating, with men having the most control and showing affection initially (Ward, 1990). In fact, some researchers have suggested that men were the one who had the most to gain from loving relationships (Fletcher, 1999). More recently, however, the need for marriage has decreased and it has been found that, with women coming into more independence both politically, socially, and financially than ever before, there is less need for marriage (Kaufman \& Goldscheider,2007).

Dating applications and the internet has given women the ability to find their own partner and initiate a romantic relationship even easier (Hobbs, Owen \& Gerber, 2017; Bivens \& Hoque, 2018). With technology making the search for a partner much more accessible and convenient, it has become much less necessary for men to make the first move, which I argue may result in the misconception that women are more eager to find love and feel love sooner than men, simply because they are now able to find love on their own. But, there is still a pressure upon both males and females to adhere to these roles of the courter and the courted, and it is crucial to examine the many sources that influence both the expectations and realities of this beginning phase of heteronormative relationships.

Furthermore, what these expectations and realities imply about the later outcomes of such relationships, particularly in a modern sense should also be examined. Monogamy is currently the norm of relationships in western society. A study conducted by Balzarini, Shumlich, Kohut and Campbell looked at individuals of monogamous, polyamorous, open and swinging relationships to determine what relationships was perceived to be most desirable and examine the stigma around CNM relationships (2018). Relatedly, more research has been conducted on the negatives of monogamous relationships and shines light on the benefits of non-monogamous relationships (Green, Valleriani \& Adam, 2016). Green, Valleriani and Adam's research into the opinions on monoga- 
mous versus non-monogamous relationships was conducted using groups of heterosexual men and women, as well as gay and lesbian individuals (2016). This research aids in my explanation of the changing norms and ideals around marriage and love. Finally, research from Campbell, Wright and Flores discovers the marriage expectations of newly married women, including their expectation of divorce, infidelity, and important aspects of a romantic relationships (2012). This research is limited in its assessment of whether or not women prefer monogamy, although it does aid in my discussion of whether monogamous relationships are still the best institution of love in an evolving society. Thus, with this research I intend to demonstrate why gendered expectations with regard to love differ from reality through changes in courtship norms and visual media exposure at a young age, and whether the advancements in technology and the increase in non-monogamous relationships affect expectations and realities of love.

\section{Courtship Norms}

Culture, being one form of a person's identity, can influence thoughts, beliefs and values, thus also influencing one's emotional expectations between genders. In one study, researchers analyzed data given by European-American, African-American, Asian-American and HispanicAmerican groups who were asked to associate emotions with a specific gender. Although the degree to which each emotion was shown varied women were expected to express emotions of love more than men across each culture (Durik et al., 2006). This study, which has taken majority of cultures around the world, suggests that women are expected to express love more than men in most cultures in the world. As mentioned, love is realistically felt and said by men first more than women, so what changed to place the expectation on women?

Courtship and marriage pre-World War II was quite different than what western society conceptualizes it as now; "Courtship, within the context of near universal marriage, therefore constituted an important rite of passage which offered bounded opportunities to perform and refine new gender roles, whilst simultaneously permitting the re-negotiation of social status and identity," (Langhamer, 2007, p.176). Courtship, for both women and men, was the opportunity for increased status and to affirm gender roles. However, early courtship was more focused on the man compared to today. To court a woman and have her marry him, establish a home and a family, were all signs of manhood and full maturity (Fletcher, 1999, p. 430). The man, being the suitor to a woman and establishing a relationship with her, was the one chasing for love. As mentioned, love is not the only thing the man was chasing as gaining a status of maturity and manhood was extremely desired. Therefore, marriage served as an act of conformity in order to prove one's masculinity through dominance over the wife and child(ren). Sexual acts with one's wife was also idealized as another act of solidifying one's masculinity to the rest of society for one would risk reticule if he could not perform proficiently (Fletcher, 1999, p. 432).

In the early 19th century, courtships commonly composed of walks or the man driving the woman around, and eventually outings to public places such as seeing a play, often paid for and organized by the male suitor (Ward, 1990, p.92). These outings could also increase the status of both individuals. Valentines were slightly different as we know them today; rather than sending a valentine to classmates and friends, it was common for a male suitor to send a heart-felt letter to a woman on Valentine's Day (Ward, 1990, p.98). Besides Valentines, men and women would often 
exchange other types of gifts; this gift-giving gave the men an opportunity to show affection and to show the type of affection expected in return (Ward, 1990, p.99). Once engaged, it was common and sometimes expected that the man would visit the woman's home and family, attend church with her, and for the couple to actively be in public together (Ward, 1990, p.102). As one can see, pre-WWII courtship and love was quite a different process than today with an emphasis for the male to take the much larger role in the relationship. For the male, it was both about love as well as proving and solidifying their masculinity and identity to the rest of society. The man was more often than not, although not exclusively, the chaser of the woman, giving gifts, taking the woman on dates, constantly expressing his admiration to her in hopes of gaining gratitude in return. Maybe it is this hope, this expectation, for a returned expression of gratitude or of love that influences the modern expectations, despite how these expectations are more often than not the opposite of the realities.

History and time changes much, and World War II rapidly altered the way western society functioned in just under a decade. Due to men being at war, women increasingly found paying jobs and became much more independent financially from their spouse. The ideology upheld in earlier years suggesting that women needed husbands for monetary means had slowly disappeared (Kaufman \& Goldscheider, 2007, p.29). As the workforce began to see more and more women join as well as the growing women's rights movement, every part of society had changed, including dating rituals and expectations. Post-WWII also gave rise to a larger focus on emotions and sex within the monogamous marriage, as well as "...individualized satisfaction and mutually fulfilling partnerships...," (Green, Valleriani and Adam, 2016, p.416). The shift in gendered power within relationships began to change as birth control entered the market and the implementation of no-fault divorces laws in the United States in the 1970s (Campbell, Wright \& Flores, 2012). With such advances in women's rights and the power they held, it can be argued that the increase in female independence and decrease requirement for men to court the woman has resulted in the power shift between genders in romantic relationships and thus whom is expected to show affection within the heterosexual relationship has also shifted. The man was no longer courting the woman, rather it began to become more equal in pursuit of a partner and more and more women began to take charge. This increase in women taking their search for a relationship into their own hands may have falsely signified a greater need for love and romance, suggesting that women were more ready to fall in love and express such love in a new relationship.

\section{Visual Media Exposure}

Media exposure may be one of the most important social institutions to a young person in an age of technological advancement. Television shows, books and movies often influence the way in which children understand gender roles of men and women, stereotypical masculinity and femininity (Yakalı-Çamoğlu, 2019). The Disney franchise is noted as one media industry which may influence gender roles in terms of love and emotion for girls and women. Many girls of a young age look up to the princesses in Disney stories as role models, with expectations of how a girl should act and what love may truly be like once the young girl is older. Yakalı-Çamoğlu, in their research, suggests that the romantic acts portrayed in these Disney films and books, such as in Beauty and the Beast dancing following a romantic dinner or The Little Mermaid taking a boat 
out on a romantic moonlit river, reflect acts of love $(2019, \mathrm{p} .82)$. These stories and acts of romance seem to reflect the love and happiness as being dependent on the prince. The feelings of love are often first shown by the princess, who is heart-broken and unhappy, constantly on the search for love until she finds her prince. The emotions shown by the princesses and the portrayal of damsels in distress suggest that females show 'softer 'emotions such as love, happiness, sadness, and helplessness. The prince is, conversely, conveyed as a hero, is brave, and shows only strength and resilience upon finding the princess.

For young boys, comic books and super heroes are also often looked at as role models. Where princesses are conveyed as helpless and in distress, male heroes are often shown as scientists or students, but "have the ability to transform themselves into extraordinary beings with great powers" (Yakalı-Çamoğlu, 2019, p.84). Super heroes are seen as being strong and brave, just like the prince, however boys find that "[b]ecoming a "prince" connotes losing one's identity and masculinity; it means becoming a "girl", which is an unacceptable narrative in a patriarchal society," (Yakal1-Çamoğlu, 2019, p.90). Therefore, they do not often show love actions in the way that a young girl would expect based on the princes they have seen in media, and therefore "As the girls turn into women, this belief in the existence of such characters is reflected and reinforced in popular adult forms with the theme "a search for 'the one'," creating the assumption in society that girls and women yearn for love and will therefore feel and say love first in a relationship, since they supposedly are constantly on the search for love, as shown on TV.

\section{Technological Advancement}

Recent years have seen "Increases in cohabitation and non-marital childbearing, high levels of divorce, and decreases in remarriage suggest that marriage is a less enduring and less central adult role," and therefore marriage may no longer be necessary (Kaufman \& Goldscheider, 2007, p.29). With the marriage commitment becoming less of a requirement for women as they no longer had to rely on men for status or income, the question becomes, why does society still expect women to express and feel love before men? I argue that due to the increase of independence and in an age of technological advances, women now have more autonomy and choice in their dating and love life, hence giving the impression that women love more or sooner than men, when in fact they simply are given more freedom and options.

With new technology such as dating applications (dating apps), "the internet has become a powerful 'social intermediary'," giving all individuals access to dating (Hobbs et al., 2017, p.272). For example, dating apps such as Bumble have been created to be a 'feminist app', different from most apps as women must be the first person send a message to the person of their choice based on a photograph and brief biography (Bivens \& Hoque, 2018, p.442). This means that men cannot message the woman first and therefore the woman holds the power in the relationship. Giving women the power in the relationship in this way changes the dating world as it was once known. The woman no longer relies on the man and is no longer the damsel in distress; rather, the woman is now given the ability to find her own partner and has the ability (socially and economically) to pay for dates and marry whomever she please. To some, this may be seen as the woman searching 
for a husband and for love, yearning for a partner and therefore is ready to express love sooner in a relationship. In fact, the opposite may be true; a study found that "...37 per- cent of men feel that a man can have a fully satisfying life without marriage, 59 percent of women feel that a woman can have a fully satisfying life without marriage," (Kaufman \& Goldscheider, 2007, p.35). Therefore, although it may seem that women are searching for love and therefore willing to say and feel love sooner, in reality the need for love and marriage is becoming less of a necessity for women.

\section{Monogamy as an Obligation}

Having now discussed the societal reasons for the misconception that women say and feel love first in a heterosexual relationship, it is important to look at the broader social institution of monogamous relationships and consider whether or not the institution itself is still relevant. The expectation and reality around love has proven to differ, with women being expected to love sooner and men realistically loving and saying "I love you" sooner in a relationship. However, I question whether the reality and expectations around relationships and marriage themselves have also changed. Monogamy has long since been the social norm in western society; although, research has found that non-monogamous relationships are on the rise. It has been found that $4-5 \%$ of Americans practice consensual non-monogamous relationships with approximately $20 \%$ having had experience with consensual non-monogamous relationships in their lifetime (Balzarini et al., 2018). This is further evidence that dating and marriage norms in our society are changing, but how does this affect our expectations and perceived reality of love and who loves first?

First, I would like to address the changes of monogamous relationships and the failures of such relationships in current western society. Rates of infidelity have increased within monogamous relationships, now being 10-25\% of monogamous relationships having some history of infidelity (Green, Valleriani and Adam, 2016, p.417). Infidelity has been reported to be caused by dissatisfaction within the relationship and results in strain of the emotional and physical well-being of both partners within the monogamous relationship (Green, Valleriani and Adam, 2016). The reason for such an increase in infidelity rates among monogamous relationships stems from the societal shifts that occurred after WWII, as examined earlier in this paper. Campbell, Wright and Flores explain in their article about women's marital expectations and experiences that now that women no longer rely on marriage for financial security, relationships now focus more on individual fulfillment rather than mutual love, therefore marriage as an institution has become more vulnerable and fragile, ultimately leading to infidelity and divorce (2012, p. 108).

In fact, divorce rates among monogamous relationships have risen to 50\% (Campbell, Wright \& Flores, 2012, p. 119). One study showed that of 197 married women in the sample, 74\% had some expectation of divorce (Campbell, Wright \& Flores, 2012, p.108). Thus, as society has shifted from a necessity of marriage for family structure, finances and social status to marriage as satisfactory for the individual, the structure of relationships has also shifted. With monogamous relationships continuing to be the norm in western society, yet viewing the failure of these relationships, is it time to progress to a more inclusive and radical way of thinking about relationships?

Consensual non-monogamous relationships (CNM henceforth) is a term used to capture all non-monogamous relationships, the most popular of which are swinging, polyamory, and open relationships. CNM relationships are considered taboo in western society with stigma around pro- 
miscuity and risk of sexually transmitted diseases (STI's); as well, some individuals within CNM relationships feel dehumanized by these stigma's (Balzarini et al., 2018). However, there is some evidence that the idea of non-monogamous relationships is becoming more accepted. One study found that when asking 26 heterosexual females and 21 heterosexual males of their views of nonmonogamous marriage, just over one half of heterosexual couples reported that they believed that non-monogamous marriages are valid forms of marriage. However, though these subjects reported that they agreed with non-monogamous relationships, almost all responded that their own relationships are monogamous (Green, Valleriani \& Adam, 2016). This proves that society's views on love and relationships are changing. With regard to love and who feels it first, this begs the question: is it the social institutions of media and courtship norms that must be altered, or does love as a societal concept require the change? How might this shift away from monogamous relationships affect the perception of love and women loving first?

In the same research done by Green, Valleriani and Adam, of the heterosexual females and males in their sample, just under half of female respondents believed that marriage should only be monogamous and only one third of male respondents agreed that marriage should only be monogamous (2016, p. 422). From this evidence, significantly more females than males report that marriage should be monogamous; therefore, it could be believed that women love more because they believe more in the institution of love, or what society deems as the acceptable form love. However, as mentioned earlier in the study by Campbell, Wright and Flores, 74\% of their female respondents reported they had some expectation of divorce (2012, p. 108), which would suggest that women, in fact, believe the institution of monogamous marriage does not work. To further this, the same research found that $21 \%$ of women confessed to participating in extramarital sex (Campbell, Wright and Flores, 2012, p. 109). Through this, one can see that society's expectation and reality of women and the concept of love are vastly different.

\section{Conclusion}

In this paper, I have argued that the expectation and perceived reality of who feels love and says "I love you" first in a romantic heterosexual relationship differs due to historical changes in courtship norms and the exposure to media at a young age. I have also argued that gendered expectations of love in a romantic relationship are being challenged by technological advancements and the decreased efficiency of monogamous relationships. Women have been portrayed as expressing soft emotions, including love, more often than men who are portrayed as showing harder emotions such as anger. This perception that women love more often or earlier in the heterosexual romantic relationship than their male partners derives from multiple occurrences, including the change in power dynamic in a relationship due to post-WWII movements toward women's rights. As well, popular media such as movies and books portray women as needing a "one true love" to be saved and to live happily, influencing the understanding of gender roles and expectations in youth. It is these things which contribute to the long upheld idea that women need and crave love, therefore are willing to feel love and say "I love you" first in a relationship.

Finally, I have shown that advancements in technology allow for women to take control of her relationships and empowers women to see less of a need to be married or in a relationship at all. As well, the structure of monogamy as being the normative heterosexual relationship model is 
proving to be less and less effective, with more women being dissatisfied, and infidelity, nonmonogamy and divorce increasing. These points have shown the possibility for the structure of relationship norms and the gendered expectations within them to be out-dated and coming to be obsolete. I have shown a limited number of factors contributing to these gender expectations, therefore more research into other factors, such as education and law, may be necessary for a comprehensive account of what is causing women to still be expected to show and feel the emotion of love before their male counterparts. 


\section{References}

Balzarini, R., Shumlich, E.J., Kohut, T., Campbell, L. (2018). Dimming the "halo" around monogamy: Re-assessing stigma surrounding consensually non-monogamous romantic relationships as a function of personal relationship orientation. Frontiers in Psychology, 9, 1-13.

Bivens, R., Hoque, A.S. (2018). Programming sex, gender, and sexuality: infrastructural failures in the "feminist" dating app Bumble. Canadian Journal of Communication, 43, 441-459.

Campbell, K., Wright, D.W., Flores, C.G. (2012). Newlywed women's marital expectations: lifelong monogamy? Journal of Divorce \& Remarriage, 53, 108-125.

Durik, A.M., Hyde, J.S., Marks, A.C., Roy, A.L., Anaya, D., Schultz, G. (2006). Ethnicity and gender stereotypes of emotion. Sex Roles, 54, 429-445.

Fletcher, A. (1999). Manhood, the male body, courtship and the household in early modern England. The Historical Association, 84, 419-436.

Green, A.I., Valleriani, J., Adam, B. (2016). Marital monogamy as ideal and practice: The detraditionalization thesis in contemporary marriages. Journal of Marriage and Family, 78, 416430.

Harrison, M.A., Shortall, J.C. (2011). Women and men in love: Who really feels it and says it first? The Journal of Social Psychology, 151, 727-736.

Hobbs, M. Owen, S., Gerber, L. (2017). Liquid love? Dating apps, sex, relationships and the digital transformation of intimacy. Journal of Sociology, 53, 271-284.

Kaufman, G., Goldscheider, F. (2007). Do men "need" a spouse more than women?: Perceptions of the importance of marriage for men and women. The Sociology Quarterly, 48, 29-46.

Langhamer, C. (2007). Love and courtship in mid-twentieth-century England. Cambridge University Press, 50, 173-196.

Schmitt, D.P., Youn, G., Bond, B., Brooks, S., Frye, H., Johnson, S., Klesman, J., Peplinski, C., Sampias, J., Sherrill, M., Stoka, C. (2009). When will I fell love? The effects of culture, personality, and gender on the psychological tendency to love. Journal of Research in Personality, 43, 830-846.

Tucker, R.K., Marvin, M.G., Vivian, B. (1991). What constitutes a romantic act? An empirical study. Psychological Reports, 69, 651-654.

Ward, P. (1990). Courtship, love, and marriage in nineteenth-century English Canada. Montreal, Quebec: McGill-Queen's University Press.

Yakalı-Çamoğlu, D. (2019). Characters from a different story: media, narratives of love and construction of gender identities in children's worlds. At the Interface/Probing the Boundaries, $108,77-93$. 